\title{
Taq Polymerase
}

National Cancer Institute

\section{Source}

National Cancer Institute. Taq Polymerase. NCI Thesaurus. Code C17337.

A heat stable DNA-directed DNA polymerase. The enzyme is widely utilized in laboratory polymerase chain reaction applications. 